\title{
High IncRNA H19 expression as prognostic indicator: data mining in female cancers and polling analysis in non-female cancers
}

\author{
Li Peng ${ }^{1,2}$, Xiao-Qing Yuan ${ }^{3,4, *}$, Zhao-Yang Liu' ${ }^{1,2}$, Wen-Ling Li ${ }^{1,2}$, Chao-Yang Zhang ${ }^{1,2}$, \\ Ya-Qin Zhang ${ }^{1,2}$, Xi Pan ${ }^{5}$, Jun Chen ${ }^{1,2}$, Yue-Hui $\mathrm{Li}^{1,2}$, Guan-Cheng $\mathrm{Li}^{1,2, *}$ \\ ${ }^{1}$ Key Laboratory of Carcinogenesis of the Chinese Ministry of Health and the Key Laboratory of Carcinogenesis and Cancer \\ Invasion of Chinese Ministry of Education, Xiangya Hospital, Central South University, Changsha 410078, P.R. China \\ ${ }^{2}$ Cancer Research Institute, Central South University, Changsha 410078, P.R. China \\ ${ }^{3}$ Department of Clinical Pharmacology, Xiangya Hospital, Central South University, Changsha 410008, P.R. China \\ ${ }^{4}$ Institute of Clinical Pharmacology, Central South University, Hunan Key Laboratory of Pharmacogenetics, Changsha 410078, \\ P.R. China \\ ${ }^{5}$ Department of Oncology, The Third Xiangya Hospital, Central South University, Changsha 410013, P.R. China \\ *These authors have contributed equally to this work
}

Correspondence to: Guan-Cheng Li, email: ligc61@csu.edu.cn or libsun@163.com

Keywords: H19, prognosis, female cancers, TCGA, meta-analysis

Received: June 30, $2016 \quad$ Accepted: November 14, 2016

Published: December 01, 2016

\section{ABSTRACT}

Upregulation of IncRNA H19 expression is associated with an unfavorable prognosis in some cancers. However, the prognostic value of $\mathrm{H} 19$ in female-specific cancers has remained uncharacterized. In this study, the prognostic power of high H19 expression in female cancer patients from the TCGA datasets was analyzed using Kaplan-Meier survival curves and Cox's proportional hazard modeling. In addition, in a meta-analysis of non-female cancer patients from TCGA datasets and 12 independent studies, hazard ratios (HRs) with 95\% confidence interval (CI) for overall survival (OS) and disease-free survival (DFS)/relapse-free survival (RFS)/ metastasis-free survival (MFS)/progression-free survival (PFS) were pooled to assess the prognostic value of high $\mathrm{H} 19$ expression. Kaplan-Meier analysis revealed that patients with uterine corpus cancer and higher $\mathrm{H} 19$ expression had a shorter OS ( HR= 2.710, $p<0.05)$, while females with cervical cancer and increased H19 expression had a shorter RFS $(H R=2.261, p<0.05)$. Multivariate Cox regression analysis showed that high $\mathrm{H} 19$ expression could independently predict a poorer prognosis in cervical cancer patients $(H R=4.099, p<0.05)$. In the meta-analysis, patients with high $\mathrm{H} 19$ expression showed a poorer outcome in non-female cancer $(p<0.05)$. These results suggest that high IncRNA H19 expression is predictive of an unfavorable prognosis in two female cancers (uterine corpus endometrioid cancer and cervical cancer) as well as in non-female cancer patients.

\section{INTRODUCTION}

Long non-coding RNAs (lncRNAs) are regulators of many important biological processes [1,2], including cell growth, survival, migration, invasion, and differentiation [3-5]. H19 is a highly abundant, conserved, and imprinted lncRNA [6] that is overexpressed in several cancers and acts as an oncogene [7], promoting tumorigenesis and cancer progression $[8,9]$. The upregulation of H19 forebodes an unfavorable prognosis in lung cancer [10], gastric cancer [11, 12], renal cell carcinoma [13], colorectal cancer [14], and gallbladder carcinoma [15]. However, the clinical significance and prognostic value of H19 in many other human tumors and female cancers, in particular, has remained uncharacterized.

Female cancers (breast, uterine, cervical, and ovarian cancer) are common malignant tumors [16], representing 2.714 million new cases $(19.6 \%$ of cases 
in both sexes and $41.5 \%$ in women) and 1.016 million deaths worldwide (12.4\% death in both sexes and 28.6 $\%$ in women) according to the GLOBOCAN series of the International Agency for Research on Cancer [17]. The ratio of mortality to incidence is $32.5 \%$ [17], suggesting a relatively poor prognosis for female cancers. Therefore, in order to improve the prognosis of female cancers, there is an urgent need to identify novel prognostic biomarkers.

In this study, we extracted data from five studies on female cancers (uterine corpus endometrioid cancer, cervical cancer, uterine carcinosarcoma, breast cancer, and ovarian cancer) and one study on all cancers (PanCancer) from The Cancer Genome Atlas (TCGA). We evaluated the prognostic power of high lncRNA H19 expression for female cancers and pooled the prognostic ability of high H19 expression in non-female cancers according to TCGA datasets and the available literature. Our findings provide novel insights into prognostic indicators for corpus uteri and cervical cancer, and promote the clinical utility of H19 for individualized cancer treatments.

\section{RESULTS}

\section{Patient characteristics from TCGA}

Six independent datasets composed of TCGA Endometrioid Cancer $(n=199)$, Cervical Cancer $(n=308)$, Uterine Carcinosarcoma $(\mathrm{n}=57)$, Breast Invasive Carcinoma $(n=1215)$, and Ovarian Cancer $(n=266$ and $n=419)$, as well as one dataset of Pan-Cancer $(n=9755)$ were analyzed in May 2016. All patients with female cancers were female, except for 12 males who had breast cancer. Patient characteristics, including primary disease, RNAseq platform, number of patients, gender, age, TNM stage, tumor grade, tumor position, tumor residual disease (no macroscopic disease, 1-10 mm, 11-20 mm, $>20 \mathrm{~mm}$ ), lymphatic invasion, and venous invasion are shown in Table 1. There were no significant differences in clinicopathological variables between patients with high H19 expression and those with low H19 expression in patients with uterine corpus endometrioid cancer, cervical cancer, uterine carcinosarcoma, breast cancer, and ovarian cancer $(p>0.05$; Supplementary Table S1-S6).

Table 1: Basic and clinic characteristics of cancer patients in 7 cohorts from TCGA database

\begin{tabular}{|c|c|c|c|c|c|c|c|}
\hline \multirow{2}{*}{$\begin{array}{l}\text { Cohort } \\
\text { Primary } \\
\text { disease }\end{array}$} & \multirow{2}{*}{$\begin{array}{c}\text { Pan- } \\
\text { Cancer } \\
\text { cancers }\end{array}$} & \multirow{2}{*}{$\begin{array}{l}\text { Breast cancer } \\
\begin{array}{c}\text { breast invasive } \\
\text { carcinoma }\end{array}\end{array}$} & \multicolumn{2}{|c|}{ Ovarian cancer } & \multicolumn{3}{|c|}{ Uterus cancer } \\
\hline & & & $\begin{array}{r}\text { ovarian se } \\
\text { cystadenocar }\end{array}$ & $\begin{array}{l}\text { rous } \\
\text { cinoma }\end{array}$ & $\begin{array}{c}\text { uterine } \\
\text { carcinosarcoma }\end{array}$ & $\begin{array}{l}\text { uterine } \\
\text { corpus } \\
\text { endometrioid } \\
\text { carcinoma }\end{array}$ & $\begin{array}{c}\text { cervical } \& \\
\text { endocervical } \\
\text { adenocarcinoma }\end{array}$ \\
\hline $\begin{array}{l}\text { platform of } \\
\text { RNAseq }\end{array}$ & $\begin{array}{l}\text { Illumina } \\
\text { HiSeq }\end{array}$ & $\begin{array}{c}\text { IlluminaHiSeq, } \\
\text { pancan } \\
\text { normalized }\end{array}$ & $\begin{array}{c}\text { IlluminaHiSeq, } \\
\text { pancan } \\
\text { normalized }\end{array}$ & $\begin{array}{l}\text { Illumina } \\
\text { Hiseq }\end{array}$ & $\begin{array}{c}\text { Illumina } \\
\text { HiSeq, pancan } \\
\text { normalized }\end{array}$ & $\begin{array}{c}\text { Illumina } \\
\text { HiSeq, } \\
\text { pancan } \\
\text { normalized }\end{array}$ & $\begin{array}{c}\text { Illumina } \\
\text { HiSeq, pancan } \\
\text { normalized }\end{array}$ \\
\hline No. of patients & 9755 & 1215 & 266 & 419 & 57 & 199 & 308 \\
\hline \multicolumn{8}{|l|}{ Gender } \\
\hline Female & 4675 & 1184 & 266 & 419 & 57 & 199 & 308 \\
\hline Male & 4422 & 12 & 0 & 0 & 0 & 0 & 0 \\
\hline \multicolumn{8}{|l|}{ Age (years) } \\
\hline$<60$ & 4357 & 647 & 149 & 223 & 6 & 50 & 240 \\
\hline$\geq 60$ & 4359 & 549 & 117 & 196 & 51 & 127 & 65 \\
\hline \multicolumn{8}{|l|}{ Clinical stage } \\
\hline Tis & - & 1 & 0 & 0 & 0 & 0 & 0 \\
\hline I & - & 204 & 0 & 0 & 22 & 97 & 160 \\
\hline II & - & 679 & 19 & 23 & 5 & 25 & 71 \\
\hline III & - & 271 & 213 & 331 & 20 & 45 & 46 \\
\hline IV & - & 21 & 33 & 62 & 10 & 10 & 21 \\
\hline$X$ & - & 18 & 0 & 0 & 0 & 0 & 0 \\
\hline
\end{tabular}

(Continued) 


\begin{tabular}{|c|c|c|c|c|c|c|}
\hline Cohort & $\begin{array}{c}\text { Pan- } \\
\text { Cancer }\end{array}$ & Breast cancer & Ovarian cancer & & Uterus cancer & \\
\hline $\begin{array}{l}\text { Primary } \\
\text { disease }\end{array}$ & cancers & $\begin{array}{l}\text { breast invasive } \\
\text { carcinoma }\end{array}$ & $\begin{array}{c}\text { ovarian serous } \\
\text { cystadenocarcinoma }\end{array}$ & $\begin{array}{c}\text { uterine } \\
\text { carcinosarcoma }\end{array}$ & $\begin{array}{c}\text { uterine } \\
\text { corpus } \\
\text { endometrioid } \\
\text { carcinoma }\end{array}$ & $\begin{array}{c}\text { cervical \& } \\
\text { endocervical } \\
\text { adenocarcinoma }\end{array}$ \\
\hline $\begin{array}{l}\text { platform of } \\
\text { RNAseq }\end{array}$ & $\begin{array}{l}\text { Illumina } \\
\text { HiSeq }\end{array}$ & $\begin{array}{c}\text { IlluminaHiSeq, } \\
\text { pancan } \\
\text { normalized }\end{array}$ & $\begin{array}{c}\text { IlluminaHiSeq, Illumina } \\
\text { pancan } \\
\text { normalized }\end{array}$ & $\begin{array}{c}\text { Illumina } \\
\text { HiSeq, pancan } \\
\text { normalized }\end{array}$ & $\begin{array}{c}\text { Illumina } \\
\text { HiSeq, } \\
\text { pancan } \\
\text { normalized }\end{array}$ & $\begin{array}{c}\text { Illumina } \\
\text { HiSeq, pancan } \\
\text { normalized }\end{array}$ \\
\hline
\end{tabular}

$\mathrm{T}$ (tumor)

$\begin{array}{ccc}\text { Tis } & - \\ 1 & - & 311 \\ 2 & - & 691 \\ 3 & - & \\ 4 & - & 4 \\ \mathrm{X} & - & \end{array}$

$0 \quad-\quad 553$

$1 \quad-\quad 410$

$2 \quad-\quad 129$

$3 \quad-\quad 81$

$\begin{array}{lll}\mathrm{X} & - & 23\end{array}$

M (Metastasis)

$\begin{array}{ccc}0 & - & 1010 \\ 1 & - & 22 \\ X & - & 164\end{array}$

Grade

$\begin{array}{ll}\text { G1 } & - \\ \text { G2 } & - \\ \text { G3 } & - \\ \text { G4 } & - \\ \text { GB } & - \\ \text { GX } & -\end{array}$

Position

$\begin{array}{lcccc}\text { Left } & - & 625 & 34 & 56 \\ \text { Right } & - & 571 & 34 & 46 \\ \text { Bilateral } & - & & 185 & 292\end{array}$

Tumor residual disease

No

Macroscopic

disease

311

47

4

81

23

010

64

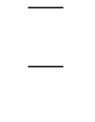

-

$\begin{array}{ccccc}1 & - & - & 13 & 20 \\ 33 & - & - & 20 & 136 \\ 225 & - & - & 140 & 118 \\ 1 & - & - & 4 & 1 \\ 1 & - & - & 0 & 0 \\ 3 & - & - & 0 & 23\end{array}$




\begin{tabular}{|c|c|c|c|c|c|c|c|}
\hline \multirow{2}{*}{$\begin{array}{l}\text { Cohort } \\
\text { Primary } \\
\text { disease }\end{array}$} & \multirow{2}{*}{$\begin{array}{c}\text { Pan- } \\
\text { Cancer }\end{array}$} & \multirow{2}{*}{$\begin{array}{c}\text { Breast cancer } \\
\begin{array}{c}\text { breast invasive } \\
\text { carcinoma }\end{array}\end{array}$} & \multicolumn{2}{|c|}{ Ovarian cancer } & \multicolumn{3}{|c|}{ Uterus cancer } \\
\hline & & & $\begin{array}{r}\text { ovarian se } \\
\text { cystadenocar }\end{array}$ & $\begin{array}{l}\text { rous } \\
\text { cinoma }\end{array}$ & $\begin{array}{c}\text { uterine } \\
\text { carcinosarcoma }\end{array}$ & $\begin{array}{c}\text { uterine } \\
\text { corpus } \\
\text { endometrioid } \\
\text { carcinoma }\end{array}$ & $\begin{array}{c}\text { cervical \& } \\
\text { endocervical } \\
\text { adenocarcinoma }\end{array}$ \\
\hline $\begin{array}{l}\text { platform of } \\
\text { RNAseq }\end{array}$ & $\begin{array}{l}\text { Illumina } \\
\text { HiSeq }\end{array}$ & $\begin{array}{c}\text { IlluminaHiSeq, } \\
\text { pancan } \\
\text { normalized }\end{array}$ & $\begin{array}{c}\text { IlluminaHiSeq, } \\
\text { pancan } \\
\text { normalized }\end{array}$ & $\begin{array}{c}\text { Illumina } \\
\text { Hiseq }\end{array}$ & $\begin{array}{c}\text { Illumina } \\
\text { HiSeq, pancan } \\
\text { normalized }\end{array}$ & $\begin{array}{l}\text { Illumina } \\
\text { HiSeq, } \\
\text { pancan } \\
\text { normalized }\end{array}$ & $\begin{array}{c}\text { Illumina } \\
\text { HiSeq, pancan } \\
\text { normalized }\end{array}$ \\
\hline $1-10 \mathrm{~mm}$ & & & 119 & 196 & & & \\
\hline $11-20 \mathrm{~mm}$ & - & - & 20 & 29 & - & - & - \\
\hline$>20 \mathrm{~mm}$ & & - & 42 & 76 & - & - & - \\
\hline \multicolumn{8}{|l|}{$\begin{array}{l}\text { Lymphatic } \\
\text { invasion }\end{array}$} \\
\hline Positive & - & - & 70 & 106 & - & - & - \\
\hline Negative & - & - & 39 & 55 & - & - & - \\
\hline \multicolumn{8}{|l|}{$\begin{array}{l}\text { Venous } \\
\text { invasion }\end{array}$} \\
\hline Positive & - & - & 44 & 65 & - & - & - \\
\hline Negative & - & - & 38 & 48 & - & - & - \\
\hline
\end{tabular}

\section{High H19 expression predicts a shorter median overall survival in uterine corpus endometrioid cancer patients}

We first evaluated the prognostic power of H19 in five female cancers. Patients with uterine corpus endometrioid cancer from the TCGA Endometrioid Cancer cohort (gene expression by RNAseq -- IlluminaHiSeq, pancan normalized, $\mathrm{n}=199$ ) who had high $\mathrm{H} 19$ expression had unfavorable overall survival (OS; $\mathrm{HR}=2.710,95 \% \mathrm{CI}$ $=1.076-6.827, p=0.0344)$, while there was no effect on relapse-free survival (RFS) time $(p>0.05)$ in comparison with those uterine corpus endometrioid cancer patients with low H19 expression (Figure 1A-1B).

Univariate and multivariate Cox's proportional hazards analyses were conducted to determine the prognostic value of H19 in the OS of uterine corpus endometrioid cancer patients. In the univariate Cox regression analysis, higher $\mathrm{H} 19$ expression $(\mathrm{HR}=2.281$, $95 \% \mathrm{CI}=1.020-5.099, p=0.045)$, heavier weight $(\mathrm{HR}$ $=0.385,95 \% \mathrm{CI}=0.148-1.002, p=0.050)$, larger $\mathrm{BMI}$ $(\mathrm{HR}=0.275,95 \% \mathrm{CI}=0.100-0.757, p=0.012)$, and higher clinical TNM stage $(\mathrm{HR}=3.526,95 \% \mathrm{CI}=1.479$ - 8.404, $p=0.004$ ) were all associated with uterine corpus endometrioid carcinoma patients' OS (Table 2). Multivariate Cox regression revealed that high $\mathrm{H} 19$ expression had no effect on OS in uterine corpus endometrioid cancer patients (Table 2). Yet, there was a prognostic impact of larger BMI
$(\mathrm{HR}=0.173,95 \% \mathrm{CI}=0.037-0.809, p=0.026)$ and higher clinical TNM stage $(\mathrm{HR}=4.834,95 \% \mathrm{CI}=1.495-15.630$, $p=0.009$ ) on OS (Table 2). Taken together, these results indicated that $\mathrm{H} 19$ predicts a shorter OS in uterine corpus endometrioid cancer patients.

\section{High H19 expression is an independent prognostic factor for cervical cancer patients' relapse-free survival}

In cervical \& endocervical cancer patients from the TCGA Cervical Cancer cohort (gene expression by RNAseq -- IlluminaHiSeq, pancan normalized, n=308), high H19 expression did not predict OS $(p>0.05)$. However, high H19 expression was associated with a shorter relapse-free survival $(\mathrm{RFS} ; \mathrm{HR}=2.261,95 \% \mathrm{CI}=1.077-4.747, p=$ 0.0310 ) in cervical cancer patients when compared with patients with low H19 expression (Figure 1C-1D).

Univariate and multivariate Cox's proportional hazards analyses were conducted to determine the prognostic value of $\mathrm{H} 19$ on RFS of cervical cancer patients. In the univariate Cox regression analysis, there was a prognostic influence of higher $\mathrm{H} 19$ expression $(\mathrm{HR}=2.397$, $95 \% \mathrm{CI}=1.055-5.442, p=0.037)$, higher Node $(\mathrm{N})$ phase of TNM stage $(\mathrm{HR}=3.759,95 \% \mathrm{CI}=1.535-9.203, p$ $=0.004)$, and tobacco smoking $(\mathrm{HR}=0.405,95 \% \mathrm{CI}=$ $0.170-0.968, p=0.042$ ) on RFS in cervical cancer patients (Table 3). Multivariate Cox regression further verified the 

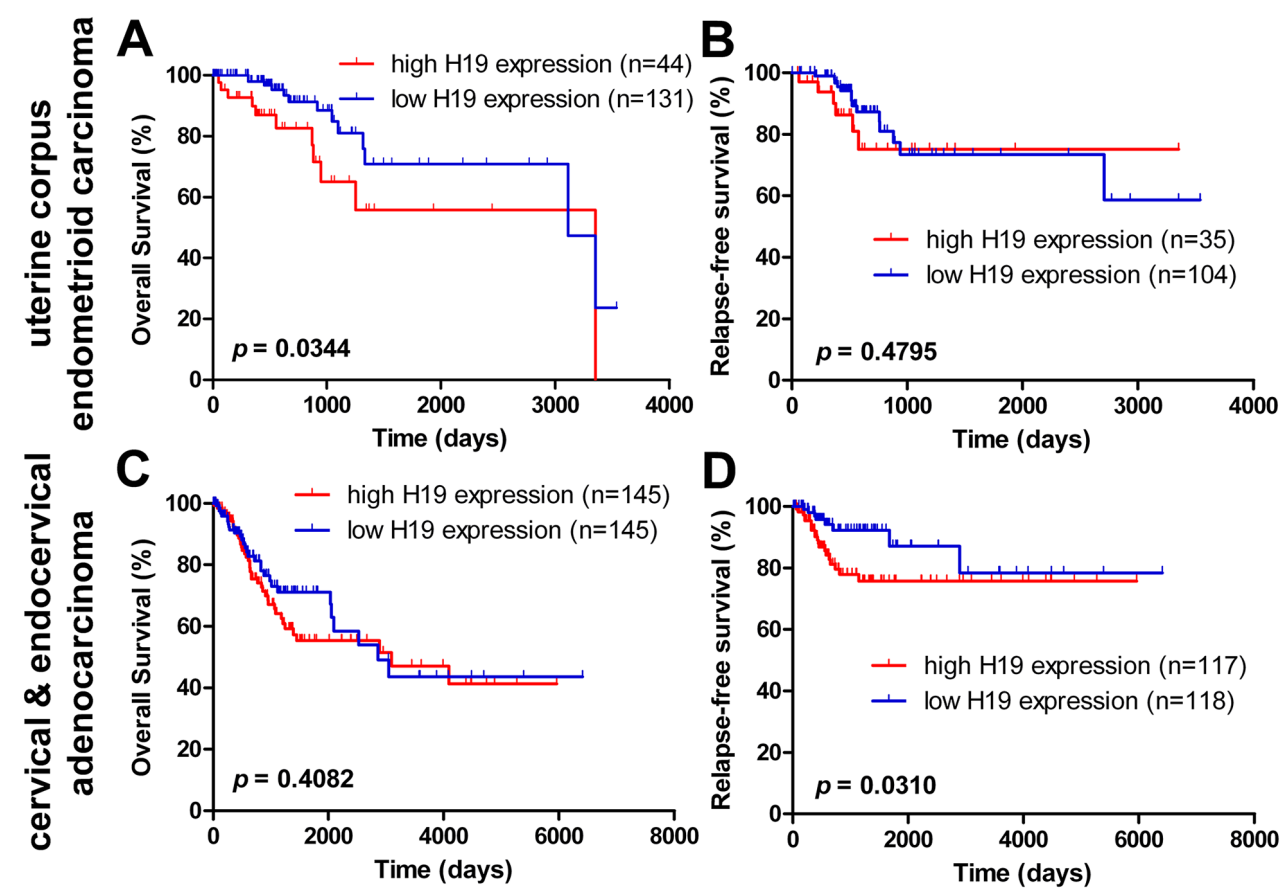

Figure 1: Kaplan-Meier estimate of overall survival and relapse-free survival of $\mathrm{H} 19$ expression in endometrioid carcinoma and cervical cancer patients. The overall survival (OS) A. and relapse-free survival (RFS) B. of H19 expression in uterine corpus cancer patients from TCGA dataset (Uterine Corpus Endometrioid Carcinoma - IlluminaHiSeq - pancan normalized; $\mathrm{n}_{\text {os }}=175$ and $n_{\text {RFS }}=139$ ). The OS C. and RFS D. of H19 expression in cervical cancer patients from the TCGA dataset (Cervical \& Endocervical Adenocarcinoma - IlluminaHiSeq - pancan normalized and Uterine Corpus Endometrioid Carcinoma - IlluminaHiSeq - pancan normalized, $\mathrm{n}_{\mathrm{OS}}=290$ and $\left.\mathrm{n}_{\mathrm{RFS}}=235\right)$.

Table 2: Univariate and multivariate analysis of clinic pathologic factors for overall survival of 199 uterine corpus endometrioid carcinoma patients

\begin{tabular}{|c|c|c|c|c|c|c|}
\hline \multirow[t]{2}{*}{ Risk factors } & \multicolumn{3}{|c|}{ Univariate analysis } & \multicolumn{3}{|c|}{ Multivariate analysis } \\
\hline & HR & $95 \%$ CI & $p$ & HR & $95 \% \mathrm{CI}$ & $p$ \\
\hline H19 expression (high, vs. low) & 2.281 & $1.020-5.099$ & 0.045 & 1.223 & $0.445-3.366$ & 0.634 \\
\hline Age $(\geq 60$, vs. $<60)$ & 1.362 & $0.562-3.298$ & 0.494 & & & \\
\hline Weight $(\geq 80$, vs. $<80)$ & 0.385 & $0.148-1.002$ & 0.050 & 1.781 & $0.226-2.347$ & 0.667 \\
\hline Height $(\geq 161$, vs. $<161)$ & 1.026 & $0.450-2.335$ & 0.952 & & & \\
\hline BMI $(\geq 25$, vs. $<25)$ & 0.037 & $0.000-23.998$ & 0.318 & & & \\
\hline BMI $(\geq 15.625$, vs. $<15.625)$ & 0.275 & $0.100-0.757$ & 0.012 & 0.173 & $0.037-0.809$ & 0.026 \\
\hline Clinical stage (III- IV, vs. I-II) & 3.526 & $1.479-8.404$ & 0.004 & 4.834 & $1.495-15.630$ & 0.009 \\
\hline Grade (3-4, vs. 1-2) & 26.927 & $0.192-3373.954$ & 0.192 & & & \\
\hline Sample type (non-, vs. solid tissue normal) & 1.608 & $0.368-7.028$ & 0.528 & & & \\
\hline Colorectal cancer (positive, vs. negative) & 0.049 & $0.000-2.05 \mathrm{E} 11$ & 0.839 & & & \\
\hline Diabetes (positive, vs. negative) & 0.314 & $0.072-1.368$ & 0.123 & & & \\
\hline Hypertension (positive, vs. negative) & 0.403 & $0.146-1.114$ & 0.080 & 0.775 & $0.256-2.347$ & 0.792 \\
\hline Pregnancies $(>2$, vs. $\leqq 2)$ & 1.663 & $0.618-4.478$ & 0.314 & & & \\
\hline $\begin{array}{l}\text { Histological type (mix, vs. serous/ } \\
\text { endometrioid) }\end{array}$ & 3.095 & $0.894-10.717$ & 0.075 & 2.117 & $0.568-7.890$ & 0.330 \\
\hline Menopause status (Post, vs. Peri/Pre) & 2.160 & $0.289-16.118$ & 0.453 & & & \\
\hline
\end{tabular}


prognostic value of higher $\mathrm{H} 19$ expression $(\mathrm{HR}=4.099$, $95 \% \mathrm{CI}=1.156-14.538, p=0.029)$ and higher Node $(\mathrm{N})$ phase of TNM stage $(\mathrm{HR}=4.186,95 \% \mathrm{CI}=1.614-10.856$, $p=0.003$ ) served as independent prognostic predictors for RFS in cervical cancer patients. In sum, these results indicated that $\mathrm{H} 19$ serves as a prognostic indicator of RFS in cervical cancer patients (Table 3).

\section{Prognostic power of high H19 expression in other female cancer patients}

We also evaluated the prognostic ability of high H19 expression in three additional female cancer subtypes including uterine carcinosarcoma $(\mathrm{n}=57)$, breast cancer $(n=1215)$, and ovarian cancer $(n=266$ and $n=419)$ from the TCGA datasets. There were no significant differences on OS or RFS between patients with higher H19 expression and those with lower H19 expression in these three cancers $(p>0.05$, Supplementary Figure S2A-S2F).

\section{Prognostic analysis of high $\mathrm{H} 19$ expression in non-female cancer patients from the TCGA cohorts}

Because the above results suggested that high $\mathrm{H} 19$ expression could predict an unfavorable prognosis in some female cancer patients, we next assessed whether it had prognostic ability in patients with non-female cancer (Pan-cancer excluding the female cancers, including 25 cancers). As there are large differences in mean H19 expression among different kinds of tumors (data not shown), the HRs with $95 \%$ CI of OS and RFS from Kaplan-Meier analysis for non-female cancers of TCGA cohorts were pooled to assess the prognostic value of high H19 expression. A shorter OS (pooling HR $=1.19,95 \%$ $\mathrm{CI}=1.08-1.31, p=0.0004)$ was observed in non-female cancer patients with higher H19 expression compared with those with lower H19 expression under a fixedeffect model (Figure 2, Supplementary Figure S3). Yet, there were no differences in RFS between the groups of non-female cancer patients with higher H19 expression and those with lower H19 expression with a fixed-effect model ( $p>0.05$, Supplementary Figure S4-S5). It is worth noting that there was no significant heterogeneity $\left(p^{\prime}=\right.$ $\left.0.60, I^{2}=0 \% ; p^{\prime}=0.72, I^{2}=0 \%\right)$ in either OS or RFS (Supplementary Figure S6).

\section{Characteristics of publications in meta-analysis}

To further validate the prognostic value of high H19 expression in cancer patients, twelve studies [11-15, 18-24] totaling 878 individuals were incorporated into a meta-analysis. The clinicopathological characteristics of these patients are shown in Table 4. Sample sizes ranged from 24 to 128 patients. Three studies were designed for hepatic cancer, three for gastric cancer, one for non-small cell lung cancer, one for colorectal cancer, one for clear cell renal cell carcinoma, one for bladder cancer, one

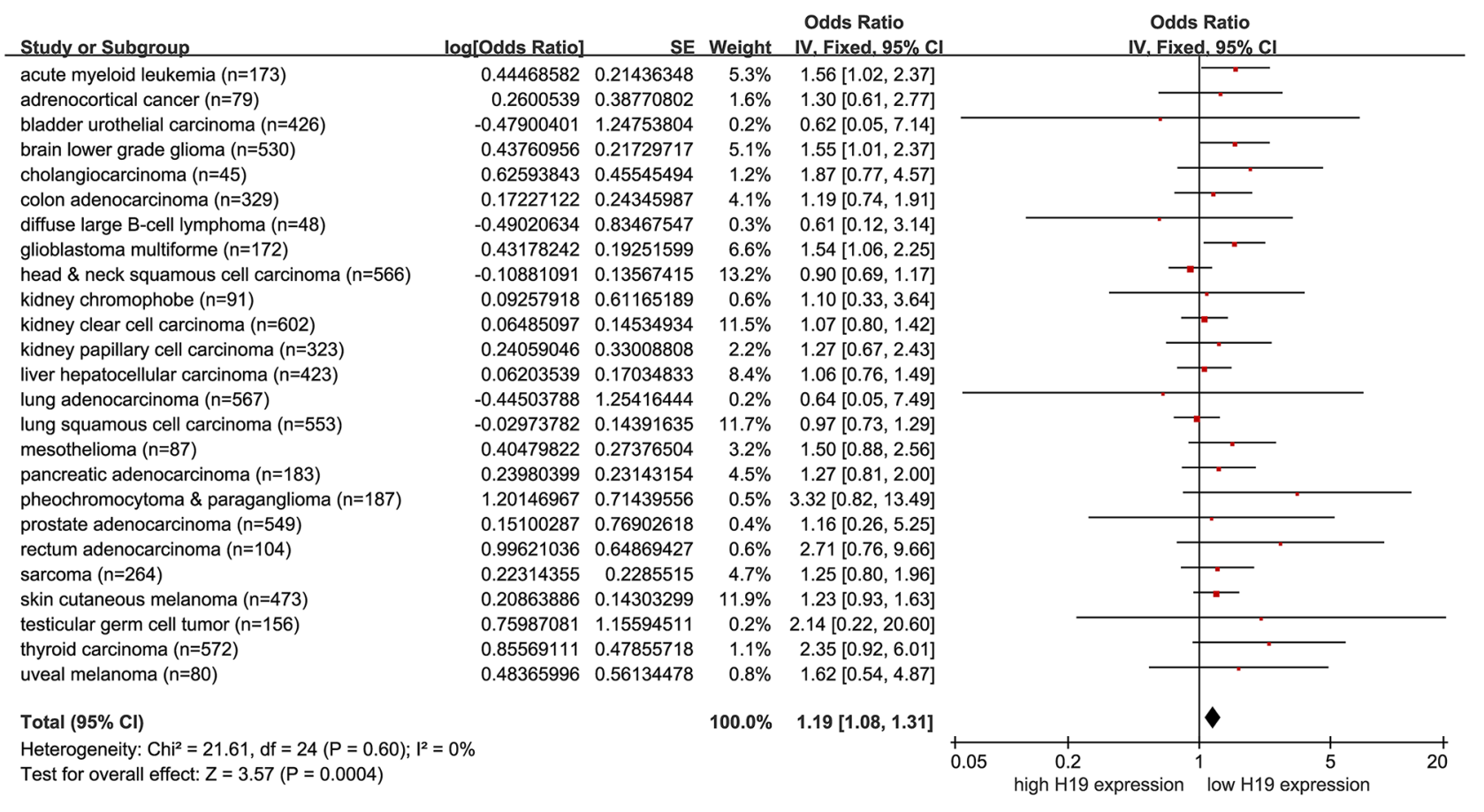

Figure 2: Pooling analysis estimate of overall survival of $\mathrm{H} 19$ expression in non-female cancer patients from the pancancer cohort. The overall survival (OS) of H19 expression in non-female cancer patients from the Kaplan-Meier analaysis of the PanCancer dataset. The size of the blocks or diamonds represents the weight of the random-effect model in the meta-analysis. HR $>1$ indicates that high $\mathrm{H} 19$ expression is correlated with a more unfavorable OS. 
Table 3: Univariate and multivariate analysis of clinic pathologic factors for relapse-free survival of 308 cervical \& endocervical adenocarcinoma patients

\begin{tabular}{|c|c|c|c|c|c|c|}
\hline \multirow[t]{2}{*}{ Risk factors } & \multicolumn{3}{|c|}{ Univariate analysis } & \multicolumn{3}{|c|}{ Multivariate analysis } \\
\hline & HR & $95 \%$ CI & $p$ & HR & $95 \%$ CI & $p$ \\
\hline H19 expression (high, vs. low) & 2.397 & $1.055-5.442$ & 0.037 & 4.099 & $1.156-14.538$ & 0.029 \\
\hline Age $(\geq 60$, vs. $<60)$ & 0.938 & $0.380-2.316$ & 0.890 & & & \\
\hline Weight $(\geq 71$, vs. $<71)$ & 0.871 & $0.402-1.885$ & 0.725 & & & \\
\hline Height $(\geq 161$, vs. $<161)$ & 0.720 & $0.298-1.739$ & 0.465 & & & \\
\hline BMI $(\geq 25$, vs. $<25)$ & 0.049 & $0.000-1.266 \mathrm{E} 50$ & 0.960 & & & \\
\hline BMI $(>13.304$, vs. $<13.304)$ & 0.548 & $0.227-1.324$ & 0.181 & & & \\
\hline Clinical stage (III- IV, vs. I-II) & 0.505 & $0.152-1.674$ & 0.264 & & & \\
\hline T (Tumor; 3-4, vs. 1-2) & 0.768 & $0.180-3.283$ & 0.722 & & & \\
\hline N (Node; 1, vs. 0) & 3.759 & $1.535-9.203$ & 0.004 & 4.186 & $1.614-10.856$ & 0.003 \\
\hline M (Metastasis; 1, vs. 0) & 0.045 & $0.000-2410.453$ & 0.577 & & & \\
\hline Grade (3, vs. 1-2) & 1.554 & $0.740-3.263$ & 0.244 & & & \\
\hline Sample type (non-, vs. solid tissue normal) & 20.622 & $0.000-3.065 \mathrm{E} 7$ & 0.676 & & & \\
\hline Pregnancies $(>2, \mathrm{vs} . \leqq 2)$ & 0.957 & $0.361-2.539$ & 0.929 & & & \\
\hline Ectopic pregnancies (>1, vs. 0 ) & 0.041 & $0.000-51.985$ & 0.381 & & & \\
\hline Pregnancy spontaneous abortion (>1, vs. 0 ) & 0.804 & $0.279-2.317$ & 0.686 & & & \\
\hline Tobacco smoking (yes, vs. no) & 0.405 & $0.170-0.968$ & 0.042 & 0.342 & $0.096-1.211$ & 0.096 \\
\hline $\begin{array}{l}\text { Tobacco smoking (current, vs. non/ } \\
\text { reformed) }\end{array}$ & 0.456 & $0.157-1.327$ & 0.149 & & & \\
\hline Histological type (Squamous, vs. others) & 1.376 & $0.477-3.969$ & 0.554 & & & \\
\hline HPV (HPV16/18, vs. others) & 1.172 & $0.106-12.978$ & 0.897 & & & \\
\hline Menopause status (Post, vs. Peri/Pre) & 0.516 & $0.205-1.301$ & 0.161 & & & \\
\hline
\end{tabular}

for gallbladder cancer, and one for glioblastoma. H19 expression was detected in two studies by ISH and in ten by RT-PCR (Table 4).

\section{A meta-analysis to assess the prognostic power of H19 in non-female cancers}

As shown in Figure 3, data were derived from univariate Cox analysis of 8 studies, totaling 615 nonfemale cancer patients. Under a random-effect model, non-female cancer patients with high $\mathrm{H} 19$ expression had shorter OS than those with low H19 expression (Figure 3; pooling $\mathrm{HR}=1.33,95 \% \mathrm{CI}=1.11-1.59, p=0.002$ ). In addition, data were derived from multivariate Cox analysis of 5 studies, totaling 453 patients. With a random-effect model, shorter OS was observed in non-female cancer patients with high $\mathrm{H} 19$ expression than those with low $\mathrm{H} 19$ expression (Figure 4; pooling $\mathrm{HR}=1.31,95 \% \mathrm{CI}=$ $1.09-1.59, p=0.004)$. These results suggested that high H19 expression could predict inferior clinical outcomes on OS time in non-female cancer patients.
To assess RFS, disease-free survival (DFS), metastasis-free survival (MFS), and progression-free survival (PFS), data were extracted from univariate Cox analysis of 7 studies, totaling 538 non-female cancer patients. As shown in Figure 5, there was no heterogeneity ( $\left.p^{\prime}=0.54, I^{2}=0 \% ; p^{\prime}=0.80, I^{2}=0 \%\right)$ in DFS or DFS/RFS/ MFS/PFS. With a fixed-effect model, shorter DFS (pooling $\mathrm{HR}=1.50,95 \% \mathrm{CI}=1.22-1.83, p<0.0001)$ and DFS/ RFS/MFS/PFS (pooling HR $=1.43,95 \% \mathrm{CI}=1.21-1.69$, $p=0.004)$ were seen in non-female cancer patients with higher $\mathrm{H} 19$ expression in comparison to those with lower H19 expression (Figure 5). Data were then derived from multivariate Cox analysis of 2 studies, totaling 211 patients. With a fixed-effect model, non-female cancer patients with high $\mathrm{H} 19$ expression had a shorter DFS than those with low H19 expression (Figure 6; pooling $\mathrm{HR}=1.43,95 \% \mathrm{CI}=$ $1.23-1.66, p<0.0001)$. These results suggested that high H19 expression could predict an adverse prognosis on DFS or DFS/RFS/MFS/PFS in non-female cancer patients, and predict adverse OS and DFS/RFS/MFS/PFS in non-female cancer patients by pooling meta-analysis. 
Table 4: Characteristics of the eligible studies in meta-analysis

\begin{tabular}{|c|c|c|c|c|c|c|c|c|c|c|c|}
\hline $\begin{array}{l}\text { First } \\
\text { author }\end{array}$ & Year & Region & Age & $\begin{array}{c}\text { No of } \\
\text { patients }\end{array}$ & $\begin{array}{c}\text { Sex } \\
(\mathbf{M} / \mathbf{F})\end{array}$ & $\begin{array}{l}\text { Cancer } \\
\text { type }\end{array}$ & $\begin{array}{c}\text { Tumor } \\
\text { stage }\end{array}$ & $\begin{array}{c}\text { Detection } \\
\text { method }\end{array}$ & $\begin{array}{c}\text { Survival } \\
\text { analysis }\end{array}$ & Outcomes & $\begin{array}{c}\text { Follow-up, } \\
\text { months }\end{array}$ \\
\hline I Ariel & 2000 & Israel & $68(55-81)$ & 61 & $48 / 12$ & $\begin{array}{l}\text { Bladder } \\
\text { cancer }\end{array}$ & 0-IV & ISH & Univariate & DFS & - \\
\hline N Iizuka & 2004 & Yamaguchi & & 59 & & $\mathrm{HCC}$ & I-III & RT-PCR & Univariate & RFS & - \\
\hline Y Fellig & 2005 & Israel & $\begin{array}{c}60.8(13.3- \\
80.0)\end{array}$ & 64 & $45 / 35$ & $\begin{array}{c}\text { Hepatic } \\
\text { metastases }\end{array}$ & - & ISH & Univariate & MFS; OS & - \\
\hline L Zhang & 2013 & China & - & 113 & - & $\mathrm{HCC}$ & - & qRT-PCR & Univariate & DFS & $21(1-24)$ \\
\hline EB Zhang & 2014 & China & - & 80 & $47 / 33$ & $\begin{array}{l}\text { Gastric } \\
\text { cancer }\end{array}$ & I-IV & qRT-PCR & $\begin{array}{c}\text { Univariate } \\
\text { and } \\
\text { Multivariate }\end{array}$ & OS & - \\
\hline $\mathrm{H} \mathrm{Li}$ & 2014 & China & - & 74 & $54 / 20$ & $\begin{array}{l}\text { Gastric } \\
\text { cancer }\end{array}$ & I-IV & qRT-PCR & Univariate & OS & - \\
\hline L Wang & 2015 & China & - & 92 & $57 / 35$ & $\mathrm{ccRCC}$ & I-IV & qRT-PCR & $\begin{array}{c}\text { Univariate } \\
\text { and } \\
\text { Multivariate }\end{array}$ & OS & - \\
\hline EB Zhang & 2015 & China & - & 70 & $46 / 24$ & NSCLC & I-IV & qRT-PCR & $\begin{array}{c}\text { Univariate } \\
\text { and } \\
\text { Multivariate }\end{array}$ & OS & - \\
\hline XC Jiang & 2016 & China & - & 30 & - & Glioblastoma & - & qRT-PCR & Univariate & PFS & - \\
\hline SH Wang & 2016 & China & - & 24 & $6 / 18$ & $\begin{array}{l}\text { Gallbladder } \\
\text { cancer }\end{array}$ & - & qRT-PCR & Univariate & OS & - \\
\hline JS Chen & 2016 & China & - & 128 & $79 / 49$ & $\begin{array}{l}\text { Gastric } \\
\text { cancer }\end{array}$ & - & qRT-PCR & $\begin{array}{c}\text { Univariate } \\
\text { and } \\
\text { Multivariate }\end{array}$ & DFS; OS & $36(20-48)$ \\
\hline D Han & 2016 & China & - & 83 & $40 / 43$ & $\begin{array}{c}\text { Colorectal } \\
\text { cancer }\end{array}$ & I-IV & qRT-PCR & $\begin{array}{c}\text { Univariate } \\
\text { and } \\
\text { Multivariate }\end{array}$ & DFS; OS & - \\
\hline
\end{tabular}

M/F, Male/Female; DFS, disease-free survival; HCC, Hepatocellular Carcinoma; ccRCC, Clear Cell Renal Cell Carcinoma; NSCLC, Non Small Cell Lung Cancer; ISH, in situ hybridization; qRT-PCR, quantitative real-time polymerase chain reaction; RFS, relapse-free survival; OS, overall survival; MFS, metastasis-free survival; PFS, progression-free survival; - , there is no corresponding data presented.

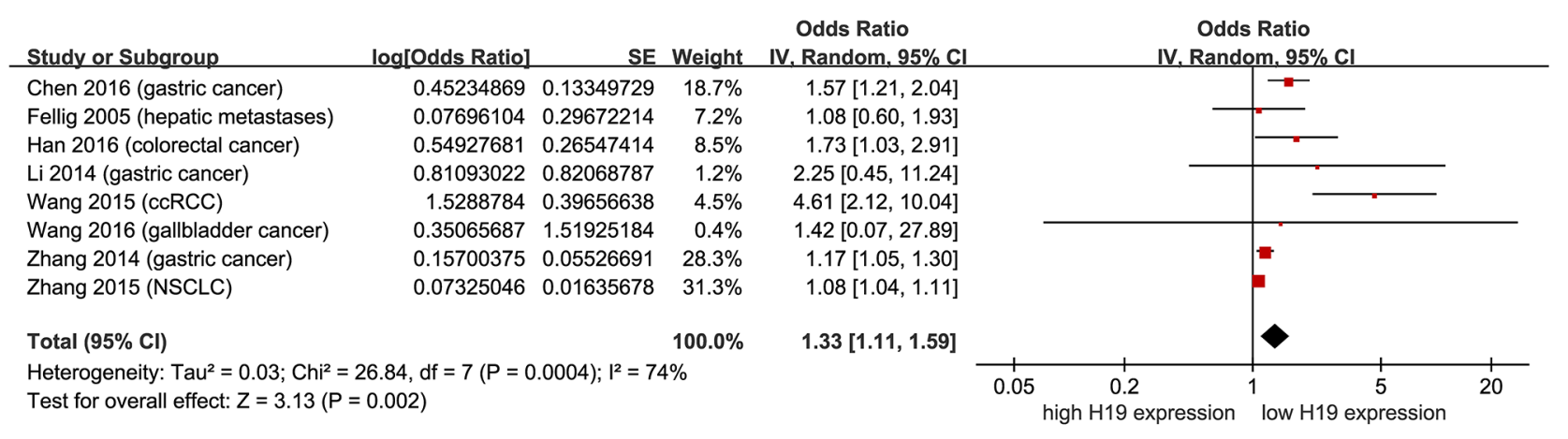

Figure 3: Meta-analysis of HRs with $95 \% \mathrm{CI}$ for overall survival from the univariate analysis of cancers from the available literature. The size of the blocks or diamonds represents the weight for the random-effect model in the meta-analysis. HR $>1$ indicates that high H19 expression is correlated with a more unfavorable overall survival (OS).

An assessment of publication bias was conducted using RevMan. The funnel plots of DFS/RFS/MFS/PFS showed that the dots were symmetrically distributed, indicating that there was no remarkable bias, and thus, our results are credible and reliable. Although the shape of funnel plots in OS outcomes did not meet global 


\begin{tabular}{|c|c|c|c|c|c|c|c|c|}
\hline Study or Subgroup & log[Odds Ratio] & SE & Weight & $\begin{array}{l}\text { Odds Ratio } \\
\text { IV, Random, } 95 \% \mathrm{CI}\end{array}$ & & $\begin{array}{r}\text { Odds } \\
\text { IV. Rando }\end{array}$ & $\begin{array}{l}\text { Ratio } \\
\text { m. } 95 \%\end{array}$ & \\
\hline Chen 2016 (gastric cancer) & 0.672434 & 0.360743 & $5.8 \%$ & $1.96[0.97,3.97]$ & & & & \\
\hline Han 2016 (colorectal cancer) & 0.35977 & 0.093284 & $25.6 \%$ & $1.43[1.19,1.72]$ & & & & \\
\hline Zhang 2014 (gastric cancer) & 0.128393 & 0.063093 & $29.5 \%$ & $1.14[1.00,1.29]$ & & & & \\
\hline Zhang 2015 (NSCLC) & 0.083422 & 0.018766 & $33.4 \%$ & $1.09[1.05,1.13]$ & & & - & \\
\hline Total $(95 \% \mathrm{CI})$ & & & $100.0 \%$ & $1.31[1.09,1.59]$ & & & & \\
\hline \multicolumn{9}{|c|}{ 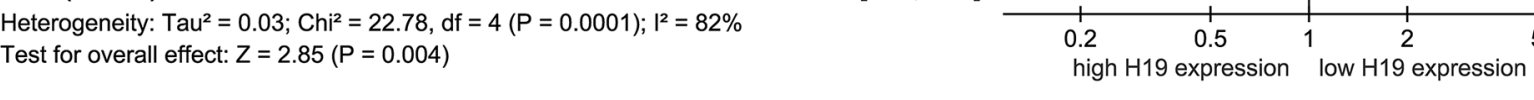 } \\
\hline
\end{tabular}

Figure 4: Meta-analysis of HRs with $95 \% \mathrm{CI}$ for overall survival from the multivariate analysis of cancers from the available literature. The size of the blocks or diamonds represents the weight for the random-effect model in the meta-analysis. HR $>1$ indicates that high H19 expression is correlated with a more unfavorable overall survival (OS).

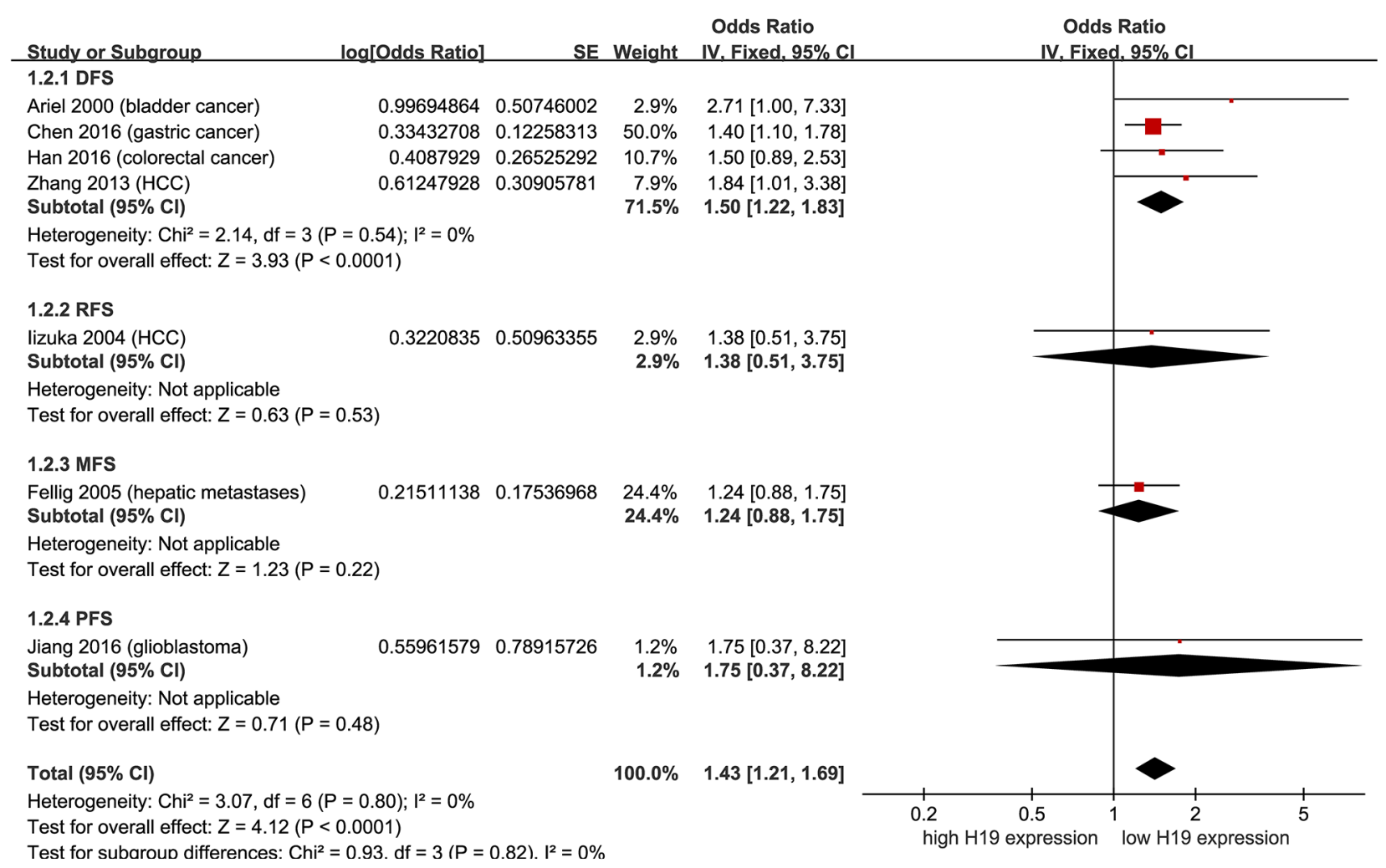

Figure 5: Meta-analysis of HRs with 95\%CI for DFS/RFS/MFS/PFS from the univariate analysis of cancers from the available literature. The size of the blocks or diamonds represents the weight for the random-effect model in the meta-analysis. HR $>1$ indicates that high H19 expression is correlated with a more unfavorable disease-free survival (DFS), relapse-free survival (RFS), metastasis-free survival (MFS) and progression-free survival (PFS).

\begin{tabular}{|c|c|c|c|c|c|c|c|}
\hline Study or Subgroup & $\log [O d d s$ Ratio] & SE & Weight & $\begin{array}{l}\text { Odds Ratio } \\
\text { IV, Fixed, } 95 \% \mathrm{CI}\end{array}$ & $\begin{array}{l}\text { Odd: } \\
\text { IV, Fixe }\end{array}$ & $\begin{array}{l}\text { Is Ratio } \\
\text { ed, } 95 \% \mathrm{Cl}\end{array}$ & \\
\hline Chen 2016 (gastric cancer) & 0.252314 & 0.127548 & $36.0 \%$ & $1.29[1.00,1.65]$ & & & 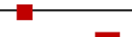 \\
\hline Han 2016 (colorectal cancer) & 0.419368 & 0.095683 & $64.0 \%$ & $1.52[1.26,1.83]$ & & & \\
\hline Total $(95 \% \mathrm{Cl})$ & & & $100.0 \%$ & $1.43[1.23,1.66]$ & & & \\
\hline \multicolumn{5}{|c|}{$\begin{array}{l}\text { Heterogeneity: } C h i^{2}=1.10, d f=1(P=0.29) ;\left.\right|^{2}=9 \% \\
\text { Test for overall effect: } Z=4.69(P<0.00001)\end{array}$} & $\begin{array}{cc}0.7 & 0.85 \\
\text { high } \mathrm{H} 19 & \text { expression }\end{array}$ & 11.2 & $\begin{array}{r}1.5 \\
\text { expression }\end{array}$ \\
\hline
\end{tabular}

Figure 6: Meta-analysis of $\mathrm{HRs}$ with $95 \% \mathrm{CI}$ for disease-free survival from the multivariate analysis of cancers from the available literature. The size of the blocks or diamonds represents the weight for the random-effect model in the meta-analysis. HR $>1$ indicates that high H19 expression is correlated with a more unfavorable disease-free survival (DFS). 
symmetry, random-effect models were used and thus our results merit consideration. The results of funnel plot are shown in Supplementary Figure S7.

\section{DISCUSSION}

Although there have been considerable advances in the development of therapies, the overall outcomes of patients with female cancers remain dismal [17]. Thus, it is necessary to discover new prognostic biomarkers and therapeutic targets. This study found that lncRNA H19 expression acts as a novel prognostic factor for uterine corpus endometrioid cancer and cervical cancer, as well as a prognostic indicator of non-female cancers. LncRNA $\mathrm{H} 19$, one of the first imprinted genes to be identified, is expressed in both embryonic and extra-embryonic cell lineages [25]. H19 is located at chromosome 11p15.5 encoding a $2.3 \mathrm{~kb}$ lncRNA [26], is frequently deregulated in tumors, and contributes to both cancer initiation and progression [27]. Thus, H19 may play an indispensable role in the pathogenesis of cancers. In recent years, there have been a growing number of reports on the biological functions of $\mathrm{H} 19$ in cancers [8, 28-33], but few studies on the prognostic significance of $\mathrm{H} 19$ expression in cancers, especially female cancers. Therefore, we focused on the evaluation of lncRNA H19 as an outcome predictor in female cancers.

Female cancers, including cancers of the breast, uterus, ovary, and cervix, account for over $40 \%$ of newly diagnosed malignancies and for approximately $30 \%$ of malignancy-associated deaths in women worldwide [17], and have a relatively poor prognosis [34]. In order to assess the potential prognostic value of H19 expression in female cancers, we analyzed six datasets for female cancers from TCGA, and discovered that high expression of H19 had an unfavorable prognostic influence on OS and RFS in uterine corpus endometrioid cancer and cervical cancer, but not in breast cancer and ovarian cancer. Although there were no statistical differences between the two groups of higher and lower H19 expression in breast or ovarian cancer, there was an "HR $>1$ " in almost all of our analyses of breast and ovarian cancer.

To understand the extensive role of H19 in cancers, we then implemented a meta-analysis of Kaplan-Meier survival analysis to evaluate the prognostic power of H19 in non-female cancers ( 25 common cancers) from TCGA. Consistent with some reports that H19 expression could serve as a poor prognostic factor [12-14, 18, 23, 24], our results further indicated that high expression of $\mathrm{H} 19$ predicted an unfavorable prognosis in non-female cancer patients. However, there is still controversy about whether H19 expression can predict the prognosis of certain cancers. Some studies showed negative findings on RFS/ MFS and OS $[19,20]$. Thus, it was necessary to carry out a meta-analysis to further elaborate the prognostic value of H19 expression based on the published literature. These meta-analysis results showed that high $\mathrm{H} 19$ expression may serve as a poor prognostic indicator in cancer patients which were in line with our pooling analysis based upon the TCGA database.

In conclusion, we found that high lncRNA H19 expression predicted an inferior prognosis in two female cancers (uterine corpus endometrioid cancer and cervical cancer), as well as in non-female cancer patients. We also propose a cost-efficient and effective way to identify prognostic biomarkers and even provide an insight for the predicted outcome of cancer patients. In the future, further studies with larger samples are required to ascertain the prognostic significance of H19 expression in cancers, especially in female cancers. Also, the biological functions and molecular mechanisms of lncRNA H19 in cervical cancer and uterine corpus endometrioid cancer are worthy of further research to furnish experimental evidence for its utility as a potential biomarker of disease prognosis and precision treatment.

\section{MATERIALS AND METHODS}

\section{Data extracted from the TCGA database}

Six independent datasets including the information on mRNA expression and clinical features of female cancers as well as one dataset on Pan-Cancer ( $\mathrm{n}=9755$ by IlluminaHiSeq, 31 cancers with available expression and survival data) were obtained from the UCSC Cancer Genomics Browser of TCGA (https://genomecancer.soe.ucsc.edu/). The six cohorts were composed of: one breast cancer $(\mathrm{n}=1215$ for Breast Invasive Carcinoma by pancan normalized IlluminaHiSeq), three uterine cancer $(\mathrm{n}=57$ for Uterine Carcinosarcoma, $\mathrm{n}=199$ for Uterine Corpus Endometrioid Carcinoma and $\mathrm{n}=308$ for Cervical Squamous Cell Carcinoma and Endocervical Adenocarcinoma, all by pancan normalized IlluminaHiSeq), and two ovarian cancer $(\mathrm{n}=266$ and $\mathrm{n}=419$ for Ovarian Serous Cystadenocarcinoma by pancan normalized IlluminaHiSeq and IlluminaHiseq, respectively). Then, we evaluated the association of IncRNA H19 expression with OS and/or RFS of three female cancers in the six cohorts. Furthermore, we extracted the expression and survival data of 25 nonfemale cancers (including acute myeloid leukemia, adrenocortical cancer, bladder urothelial carcinoma, brain lower grade glioma, cholangiocarcinoma, colon adenocarcinoma, diffuse large B-cell lymphoma, glioblastoma multiforme, head \& neck squamous cell carcinoma, kidney chromophobe, kidney clear cell carcinoma, kidney papillary cell carcinoma, liver hepatocellular carcinoma, lung adenocarcinoma, lung squamous cell carcinoma, mesothelioma, pancreatic adenocarcinoma, pheochromocytoma \& paraganglioma, prostate adenocarcinoma, rectum adenocarcinoma, sarcoma, skin cutaneous melanoma, testicular germ cell 
tumor, thyroid carcinoma and uveal melanoma) from the Pan-Cancer dataset. Also, patients were classified into two groups of higher H19 expression and lower H19 expression by median or upper quartile according to the published literature and distribution in terms of box plots on H19 expression in female cancer patients (Supplementary Figure S1). When the upper quartile was applied as a cut-off value, it indicated that higher H19 expression can only predict a significant prognosis. In addition, the associations between H19 expression and OS/RFS in these cohorts were also analyzed.

\section{Kaplan-Meier survival analysis and Cox regression analysis}

Differences between the clinicopathological data of higher H19 expression and those of lower H19 expression were assessed using the Chi-squared test. For survival analysis, OS was assessed from the day of diagnosis to the day of last follow-up, while RFS was defined as the time from the day of the first complete remission to the day of first relapse or death [35-37]. Survival curves were established using the Kaplan-Meier approach, with log-rank tests was applied to appraise the differences between the groups. HRs were estimated using Cox's proportional hazards model. Univariate and multivariate Cox models for the prognostic effect of H19 expression on OS/RFS in female cancer patients from the TCGA were analyzed. SPSS 17.0 software (IBM, Chicago, USA) was used to conduct statistical analysis and a two-sided $p$-value $<0.05$ was regarded as statistical significance. All survival-related figures were plotted in GraphPad Prism 5 (GraphPad, La Jolla, USA).

\section{Literature search for meta-analysis}

Literature were retrieved from PubMed, Embase, Web of Science, ClinicalTrials and the Cochrane Library with the following search terms: 'imprinted maternally expressed transcript', 'IncRNA H19', 'H19 RNA', 'H19', 'ASM', 'BWS', 'WT2', 'ASM1', 'D11S813E', 'LINC00008', or 'NCRNA00008'; AND 'Neoplasm', 'Neoplasms', 'Tumor', 'Tumors', 'Neoplasia', 'Cancer', 'Cancers', 'malignancy', 'sarcoma', 'adenoma', or 'melanoma'; AND 'prognostic', ‘prognosis', ‘outcome', 'outcomes', 'mortality', 'survival', 'overall survival', 'OS', 'disease-free survival', 'DFS', 'relapse-free survival', 'RFS', 'metastasis-free survival', 'MFS', 'progression-free survival', or 'PFS'.

\section{Study selection and data extraction for meta- analysis}

No related review protocol has been published. Inclusion criteria: (1) studies were full papers in English prior to April 5, 2016; (2) studies were original cohort studies; (3) patients were grouped in terms of the expression of H19, (4) studies were focused on the prognostic effect of $\mathrm{H} 19$ on patients with any type of cancer; (5) data was available on survival including OS and/or DFS/RFS/MFS/PFS. Exclusion criteria: (1) Non-human research; (2) meta-analysis, letters, expert opinions, comments, case reports and reviews; (2) duplicate publications; (3) studies without qualified data; (5) not yet published in English. Repetitive literature was managed and removed by Endnote X7.

Two researchers independently inspected all the literature that satisfied the inclusion criteria, and divergences between reviewers were settled through discussion. Information, including first author, year of publication, study region, median age, sample size, sex distribution, cancer type, tumor stage, detection method, and follow-up times from each eligible study was extracted. The corresponding HRs with 95\% CI for OS and DFS/RFS/MFS/PFS were calculated from COX univariate models from corresponding Kaplan-Meier curves by the methods [38, 39], as well as COX multivariate models.

\section{Statistics for meta-analysis}

Meta-analysis was performed with the software of Review Manager (RevMan) (version 5.3.5; the Nordic Cochrane Centre, Copenhagen, Denmark). Prognostic roles of H19 expression on OS and/or DFS/RFS/MFS/ PFS were assessed by estimation of the pooled HRs and their matching 95\% CI with the inverse variance method. Statistical heterogeneity was assessed using the chi-squared test (the significance of heterogeneity was artificially expressed as $p$ '-value to distinguish from the significance of outcomes) and $I^{2}$ statistics. When there was no significant heterogeneity ( $p^{\prime}$-value $>0.1$ and $I^{2}$ $<50 \%$ ), the pooled HRs were assessed by fixed-effect models. Otherwise, random-effect models were utilized to enhance the stability of the meta-analysis. Publication bias was appraised by Begg funnel plot and Egger's test.

\section{ACKNOWLEDGMENTS}

This work was supported by Hunan Provincial Innovation Foundation For Postgraduate (CX2016B056), the Fundamental Research Funds for the Central Universities of Central South University (2015zzts096), the Open-End Fund for the Valuable and Precision Instruments of Central South University (CSU2C2013048), and the Science and Technology Department Research Foundation of Hunan province (12JJ2052). We all thank the TCGA project team for the mass available data.

\section{Author contributions}

GCL and LP conceived and designed the manuscript. LP and XQY collected and analyzed the data, as well as drafted the manuscript. ZYL, WLL and CYZ helped to 
analyze and check the data. YQZ, JC and YHL revised critically the manuscript. All authors read and approved the final manuscript.

\section{COMPETING INTERESTS} interests.

The authors declare that they have no competing

\section{REFERENCES}

1. Castellanos-Rubio A, Fernandez-Jimenez N, Kratchmarov R, Luo X, Bhagat G, Green PH, Schneider R, Kiledjian M, Bilbao JR and Ghosh S. A long noncoding RNA associated with susceptibility to celiac disease. Science. 2016; 352:91-95.

2. Jiang B, Sun R, Fang S, Qin C, Pan X, Peng L, Li Y and Li G. Lnc-CC3 increases metastasis in cervical cancer by increasing Slug expression. Oncotarget. 2016; 7:4165041661. doi: 10.18632/oncotarget.9519.

3. Mercer TR, Dinger ME and Mattick JS. Long non-coding RNAs: insights into functions. Nat Rev Genet. 2009; 10:155-159.

4. Di Gesualdo F, Capaccioli S and Lulli M. A pathophysiological view of the long non-coding RNA world. Oncotarget. 2014; 5:10976-10996. doi: 10.18632/ oncotarget.2770.

5. Peng L, Yuan X, Jiang B, Tang Z and Li GC. LncRNAs: key players and novel insights into cervical cancer. Tumour Biol. 2016; 37:2779-2788.

6. Monnier P, Martinet C, Pontis J, Stancheva I, Ait-Si-Ali $\mathrm{S}$ and Dandolo L. H19 lncRNA controls gene expression of the Imprinted Gene Network by recruiting MBD1. Proc Natl Acad Sci U S A. 2013; 110:20693-20698.

7. Liu L, Yang J, Zhu X, Li D, Lv Z and Zhang X. Long noncoding RNA H19 competitively binds miR-17-5p to regulate YES1 expression in thyroid cancer. FEBS J. 2016; 283:2326-39.

8. Liang WC, Fu WM, Wong CW, Wang Y, Wang WM, Hu GX, Zhang L, Xiao LJ, Wan DC, Zhang JF and Waye MM. The lncRNA H19 promotes epithelial to mesenchymal transition by functioning as miRNA sponges in colorectal cancer. Oncotarget. 2015; 6:22513-22525. doi: 10.18632/ oncotarget. 4154.

9. Xia Z, Yan R, Duan F, Song C, Wang P and Wang K. Genetic Polymorphisms in Long Noncoding RNA H19 Are Associated With Susceptibility to Breast Cancer in Chinese Population. Medicine (Baltimore). 2016; 95:e2771.

10. Zhang E, Li W, Yin D, De W, Zhu L, Sun S and Han L. c-Myc-regulated long non-coding RNA H19 indicates a poor prognosis and affects cell proliferation in non-smallcell lung cancer. Tumour Biol. 2016; 37:4007-4015.

11. Chen JS, Wang YF, Zhang XQ, Lv JM, Li Y, Liu XX and Xu TP. H19 serves as a diagnostic biomarker and up-regulation of $\mathrm{H} 19$ expression contributes to poor prognosis in patients with gastric cancer. Neoplasma. 2016; 63:223-230.

12. Zhang EB, Han L, Yin DD, Kong R, De W and Chen J. c-Myc-induced, long, noncoding H19 affects cell proliferation and predicts a poor prognosis in patients with gastric cancer. Med Oncol. 2014; 31:914.

13. Wang L, Cai Y, Zhao X, Jia X, Zhang J, Liu J, Zhen H, Wang T, Tang X, Liu Y and Wang J. Down-regulated long non-coding RNA H19 inhibits carcinogenesis of renal cell carcinoma. Neoplasma. 2015; 62:412-418.

14. Han D, Gao X, Wang M, Qiao Y, Xu Y, Yang J, Dong N, He J, Sun Q, Lv G, Xu C, Tao J and Ma N. Long noncoding RNA H19 indicates a poor prognosis of colorectal cancer and promotes tumor growth by recruiting and binding to eIF4A3. Oncotarget. 2016; 7:22159-73. doi: 10.18632/ oncotarget.8063.

15. Wang SH, Wu XC, Zhang MD, Weng MZ, Zhou D and Quan ZW. Upregulation of H19 indicates a poor prognosis in gallbladder carcinoma and promotes epithelialmesenchymal transition. Am J Cancer Res. 2016; 6:15-26.

16. Rachon D. Endocrine disrupting chemicals (EDCs) and female cancer: Informing the patients. Rev Endocr Metab Disord. 2015; 16:359-364.

17. Ferlay J, Soerjomataram I, Dikshit R, Eser S, Mathers C, Rebelo M, Parkin DM, Forman D and Bray F. Cancer incidence and mortality worldwide: sources, methods and major patterns in GLOBOCAN 2012. Int J Cancer. 2015; 136:E359-386.

18. Ariel I, Sughayer M, Fellig Y, Pizov G, Ayesh S, Podeh D, Libdeh BA, Levy C, Birman T, Tykocinski ML, de Groot $\mathrm{N}$ and Hochberg A. The imprinted H19 gene is a marker of early recurrence in human bladder carcinoma. Mol Pathol. 2000; 53:320-323.

19. Iizuka N, Oka M, Tamesa T, Hamamoto Y and YamadaOkabe H. Imbalance in expression levels of insulin-like growth factor 2 and $\mathrm{H} 19$ transcripts linked to progression of hepatocellular carcinoma. Anticancer Res. 2004; 24:4085-4089.

20. Fellig Y, Ariel I, Ohana P, Schachter P, Sinelnikov I, Birman T, Ayesh S, Schneider T, de Groot N, Czerniak A and Hochberg A. H19 expression in hepatic metastases from a range of human carcinomas. J Clin Pathol. 2005; 58:1064-1068.

21. Zhang L, Yang F, Yuan JH, Yuan SX, Zhou WP, Huo XS, $\mathrm{Xu}$ D, Bi HS, Wang F and Sun SH. Epigenetic activation of the MiR-200 family contributes to H19-mediated metastasis suppression in hepatocellular carcinoma. Carcinogenesis. 2013; 34:577-586.

22. Li H, Yu B, Li J, Su L, Yan M, Zhu Z and Liu B. Overexpression of IncRNA H19 enhances carcinogenesis and metastasis of gastric cancer. Oncotarget. 2014; 5:23182329. doi: 10.18632/oncotarget.1913.

23. Zhang E, Li W, Yin D, De W, Sun S and Han L. c-Mycregulated long non-coding RNA H19 indicates a poor 
prognosis and affects cell proliferation in non-small-cell lung cancer. Tumour Biol. 2016; 3:4007-15.

24. Jiang X, Yan Y, Hu M, Chen X, Wang Y, Dai Y, Wu D, Zhuang Z and Xia H. Increased level of H19 long noncoding RNA promotes invasion, angiogenesis, and stemness of glioblastoma cells. J Neurosurg. 2016; 124:129-136.

25. Li C, Chen J, Zhang K, Feng B, Wang $\mathrm{R}$ and Chen L. Progress and Prospects of Long Noncoding RNAs (lncRNAs) in Hepatocellular Carcinoma. Cell Physiol Biochem. 2015; 36:423-434.

26. Kanduri C. Long noncoding RNAs: Lessons from genomic imprinting. Biochim Biophys Acta. 2016; 1859:102-111.

27. Matouk IJ, Halle D, Raveh E, Gilon M, Sorin V and Hochberg A. The role of the oncofetal H19 lncRNA in tumor metastasis: orchestrating the EMT-MET decision. Oncotarget. 2016; 7:3748-3765. doi: 10.18632/ oncotarget.6387.

28. Li H, Li J, Jia S, Wu M, An J, Zheng Q, Zhang W and Lu D. miR675 upregulates long noncoding RNA H19 through activating EGR1 in human liver cancer. Oncotarget. 2015; 6:31958-31984. doi: 10.18632/oncotarget.5579.

29. Zeira E, Abramovitch R, Meir K, Even Ram S, Gil Y, Bulvik B, Bromberg Z, Levkovitch O, Nahmansson N, Adar R, Reubinoff B, Galun E and Gropp M. The knockdown of H19 lncRNA reveals its regulatory role in pluripotency and tumorigenesis of human embryonic carcinoma cells. Oncotarget. 2015; 6:34691-34703. doi: 10.18632/ oncotarget.5787.

30. Jia P, Cai H, Liu X, Chen J, Ma J, Wang P, Liu Y, Zheng J and Xue Y. Long non-coding RNA H19 regulates glioma angiogenesis and the biological behavior of gliomaassociated endothelial cells by inhibiting microRNA-29a. Cancer Lett. 2016; 381:359-369.

31. Liu L, Yang J, Zhu X, Li D, Lv Z and Zhang X. Long noncoding RNA H19 competitively binds miR-17-5p to regulate YES1 expression in thyroid cancer. FEBS J. 2016; 283:2326-2339.

32. Wu T, Qu L, He G, Tian L, Li L, Zhou H, Jin Q, Ren J, Wang Y, Wang J, Kan X, Liu M, Shen J, et al. Regulation of laryngeal squamous cell cancer progression by the lncRNA H19/miR148a-3p/DNMT1 axis. Oncotarget. 2016; 7:11553-11566. doi: 10.18632/oncotarget.7270.

33. Zou T, Jaladanki SK, Liu L, Xiao L, Chung HK, Wang JY, Xu Y and Gorospe M. H19 Long Noncoding RNA Regulates Intestinal Epithelial Barrier Function via MicroRNA 675 by Interacting with RNA-Binding Protein HuR. Mol Cell Biol. 2016; 36:1332-1341.

34. Allemani C, Weir HK, Carreira H, Harewood R, Spika D, Wang XS, Bannon F, Ahn JV, Johnson CJ, Bonaventure A, Marcos-Gragera R, Stiller C, Azevedo e Silva G, et al. Global surveillance of cancer survival 1995-2009: analysis of individual data for $25,676,887$ patients from 279 population-based registries in 67 countries (CONCORD-2). Lancet. 2015; 385:977-1010.

35. Lu X, Wan F, Zhang H, Shi G and Ye D. ITGA2B and ITGA8 are predictive of prognosis in clear cell renal cell carcinoma patients. Tumour Biol. 2016; 37:253-262.

36. Yuan XQ, Zhang DY, Yan H, Yang YL, Zhu KW, Chen YH, Li X, Yin JY, Li XL, Zeng H and Chen XP. Evaluation of DNMT3A genetic polymorphisms as outcome predictors in AML patients. Oncotarget. 2016; 7:60555-60574. doi: 10.18632/oncotarget.11143.

37. Yuan XQ, Peng L, Zeng WJ, Jiang BY, Li GC and Chen XP. DNMT3A R882 Mutations Predict a Poor Prognosis in AML: A Meta-Analysis From 4474 Patients. Medicine (Baltimore). 2016; 95:e3519.

38. Tierney JF, Stewart LA, Ghersi D, Burdett S and Sydes MR. Practical methods for incorporating summary time-to-event data into meta-analysis. Trials. 2007; 8:16.

39. Parmar MK, Torri V and Stewart L. Extracting summary statistics to perform meta-analyses of the published literature for survival endpoints. Stat Med. 1998; 17:2815-2834. 